\title{
HUBUNGAN KECERDASAN EMOSIONAL DENGAN STRES KERJA PERAWAT DI RUANG RAWAT AMBUN SURI RSUD DR. ACHMAD MOCHTAR BUKITTINGGI
}

\author{
Ridhyalla Afnuhazi \\ AKPER NABILA Padang Panjang \\ Email : ridhyallaafnuhazi@yahoo.co.id
}

\begin{abstract}
The nurse has some characteristics which demand high workload and pressure. With this ability, individuals will be better able to overcome various problems that arise during the process towards adults so that they will be better able to overcome emotional challenges in modern life that are increasingly complex. Data NIOSH show 98\% the nursing profession is very high risk of stres. The purpose the study was to determine the relationship between emosional intelligence and the work stres of nurses. This study use the Quasi eksperiment design with Total Sampling Method. The sample in this study were 83 respondents. This research was conducted in Inward Dr. Achmad Mochtar Hospital Bukittinggi. The statistical test used is Chi-Square. The result of statistical test showed a significant between the relationship between emosional intelligence and the work stres of nurses with $p$-Value $=0,000(\alpha \leq 0,05)$. Based of the finding, it is expected that those who have nurse profession will intensively improve their emotional intelligence so that they will have lower of work stres.
\end{abstract}

Keywords: Emosional Intelligence, Stres Of Nurses Work

\begin{abstract}
ABSTRAK
National Institute for Occupational Safety \& Health (NIOSH) menetapkan perawat sebagai profesi yang berisiko sangat tinggi terhadap stress dan hasil penelitian Selye menunjukkan $98 \%$ alasan mengapa profesi perawat mempunyai resiko yang tinggi terpapar oleh stres. Desain penelitian ini menggunakan Deskriptif Analitik, dengan pendekatan Cross Sectional Study yaitu untuk mengetahui hubungan antara dua variabel yaitu independen dan dependen dari kelompok subjek yang bertujuan untuk mengetahui adanya hubungan kecerdasan emosional dengan stres kerja perawat di ruang rawat inap Ambun Suri RSUD Dr. Achmad Mochtar Bukittinggi, dimana pengumpulan variabel independen dan variabel dependen dilakukan bersamaan atau sekaligus. penelitian ini telah dilakukan di ruang rawat inap Ambun Suri RSUD Dr. Achmad Mochtar Bukittinggi pada bulan April - Mei 2018. Populasi dalam penelitian ini adalah perawat di seluruh ruang rawat inap Ambun Suri ada 83 orang di RSUD Dr. Achmad Mochtar Bukittinggi. Hasil yang diperoleh Terdapat hubungan yang signifikan antara kecerdasan emosional perawat dengan tingkat stres kerja Perawat di Rumah Sakit Achmad Mochtar Bukittinggi, dengan nilai $p=0,002<\alpha$ $(0,05)$,
\end{abstract}

Kata kunci: Kecerdasan emosional, stress Perawat 


\section{PENDAHULUAN}

Pelayanan kesehatan pada masa kini sudah merupakan industri jasa kesehatan utama dimana setiap rumah sakit bertanggung jawab terhadap penerima jasa pelayanan kesehatan. Keberadaan dan kualitas pelayanan kesehatan yang diberikan ditentukan oleh nilai-nilai dan harapan dari penerima jasa pelayanan tersebut. Selayaknya industri jasa pelayanan menaruh perhatian besar dan menyadari bahwa kualitas pelayanan kesehatan yang diberikan ditentukan pula oleh kualitas berbagai komponen pelayanan termasuk keperawatan dan sumber daya manusianya (Darmawan, 2008). Perawat dapat dikatakan merupakan tulang punggung pelayanan dan hadir 24 jam sehari untuk merawat dan menjaga pasien. Tanpa perawat tugas dokter akan semakin berat dalam menangani pasien, kesejahteraan pasien juga terabaikan karena perawat adalah penjalin kontak pertama dan terlama dengan pasien mengingat pelayanan keperawatan berlangsung terus menerus selama 24 jam sehari. Perawat harus selalu siaga selama 24 jam untuk melakukan tugas-tugas rutin dalam menghadapi berbagai situasi darurat seperti kondisi kesehatan pasien yang kritis, menghadapi kesulitan keluarga pasien, dan sebagainya (Purwanto, 2007).

Tenaga kesehatan khususnya perawat dalam menganalisa beban kerja dapat dilihat berdasarkan aspek-aspek tugas yang dijalankan menurut fungsi utamanya. Aspekaspek yang berhubungan dengan beban kerja adalah jumlah pasien yang dirawat, kapasitas kerja sesuai dengan pendidikan yang diperoleh, shift yang digunakan untuk mengerjakan tugas yang sesuai dengan jam kerja yang berlangsung setiap hari, serta kelengkapan fasilitas yang dapat membantu perawat menyelesaikan kerja dengan baik. (Haryani, 2008).

Penelitian dari National Institute for Occupational Safety \& Health (NIOSH) menetapkan perawat sebagai profesi yang berisiko sangat tinggi terhadap stres (Schultz \& Schultz, 1994) dan hasil penelitian Selye (1996) menunjukkan (98\%) yaitu alasan mengapa profesi perawat mempunyai resiko yang tinggi terpapar oleh stres adalah karena perawat memiliki tugas dan tanggung jawab yang sangat tinggi terhadap keselamatan nyawa manusia, selebihnya bahwa perawat hanya megalami stres ringan saat memiliki tugas dan tanggung jawab yang sangat tinggi terhadap nyawa manusia.

Perawat didalam bekerja akan sangat mempengaruhi kualitas pelayanan keperawatan yang diberikan kepada pasien. Stres dipandang sebagai realitas kehidupan setiap hari yang memerlukan perubahan untuk penyesuaian. Stres kerja berhubungan dengan emosi perawat. Perawat dalam menjalankan tugasnya selalu berhubungan dengan banyak orang sehingga untuk memperlancar hubungan tersebut diperlukan kemampuan dalam mengelola emosi, agar lebih mampu menempatkan emosi pada porsi yang tepat, memilah kepuasan dan mengatur suasana hati, individu yang pandai menyesuaikan diri dengan suasana hati individu lain atau dapat berempati, akan memiliki tingkat 
emosi yang baik dan akan lebih mudah menyesuaikan diri dalam pergaulan sosial serta lingkungannya, termasuk lingkungan kerjanya. Kemampuan tersebut dikenal dengan istilah kecerdasan emosi (Goleman, 2002).

Kecerdasan emosi atau Emotional Intelligence adalah kemampuan seseorang mengelola emosi dalam kaitannya dengan orang lain atau rangsangan dari luar. Kecerdasan emosi mencakup pengendalian diri terutama berkaitan dengan relasi, berempati kepada orang lain, mengelola rasa gembira dan sedih, semangat dan ketekunan, serta kemampuan untuk memotivasi diri (Sumardi, 2007).

Kecerdasan Emosi menuntut manusia agar dapat mengembangkan kemampuan emosional dan kemampuan sosialnya. Kemampuan emosional sendiri meliputi sadar akan keadaan emosi diri sendiri, kemampuan mengelola emosi, kemampuan memotivasi diri dan kemampuan menyatakan perasaan kepada orang lain (Tridhonanto, 2009).

Pelayanan keperawatan sangat diperlukan sosok perawat yang memiliki kecerdasan emosi yang tinggi, seseorang yang memiliki kecerdasan emosi yang tinggi memiliki kemampuan dalam mengatasi tuntutan dan tekanan lingkungan, berbagai masalah atau tantangan yang muncul dalam hidupnya daripada seseorang yang lebih rendah kecerdasan emosinya. Masalah yang sering terjadi dalam lingkungan kerja yaitu masalah dalam tuntutan kerja menghadapi masalah fisik dan psikososial (Stein, 2002).
Masalah fisik berupa terdapatnya berbagai jenis penyakit, merawat pasian gawat dan banyaknya jumlah pasien, sedangkan masalah psikososial berupa hubungan antar perawat lain, dokter, tim kesehatan lain dan hubungan antara pasien serta keluarga pasien. Untuk membina hubungan tersebut diperlukan ketrampilan emosi yaitu kemampuan mengenali emosi orang lain dan membina hubungan sosial dengan orang lain, kemampuan ini disebut sebagai kecerdasan emosi (Goleman, 2002).

Makin kompleksnya tugastugas perawat membuat perawat sangat rentan mengalami stres dalam bekerja, sehingga perawat perlu memiliki kecerdasan emosional yang tinggi di dalam menghadapi berbagai kondisi kerja (Anastasia S. K, 2008). Penelitian dari Anggra Martina (2012), yaitu tentang "Gambaran Tingkat Stres Kerja Perawat Di Ruang Rawat Inap Rumah Sakit Paru Dr. Moehammad Goenawan Partowidigdo Cisarua Bogor (RSPG)" selama 18 hari dengan 80 responden didapatkan hasil penelitian menggunakan metode desain penelitian Descriptive dengan bentuk rancangan nonprobably sampling dengan hasil lebih banyak tingkat sedang yaitu 69 orang $(86 \%)$ sedangkan responden dengan tingkat stres kerja rendah berjumlah 4 orang (5\%) dan stres kerja tingkat tinggi berjumlah 7 orang (9\%).

Penelitian dari Anastasia, S. K (2008), yaitu tentang "Hubungan Kecerdasan Emosional dengan Stres Kerja Perawat di RSUD Dr. Achamd Mochtar Bukittinggi" selama 10 hari dengan 25 responden didapatkan 
hasil penelitian menggunakan metode Descriptive analitio correlation dengan bentuk rancangan Cross sectional dengan hasil perhitungan normalitas Rata-rata tingkat kecerdasan emosional dan tingkat stres kerja masing-masing dalam kategori sedang yaitu $(80 \%)$ dan $(76 \%)$.

World Health Organization menyebutkan dari data statistik yang didapatkan pada tahun 2011 jumlah perawat di dunia mencapai 19.380.000 orang perawat dengan pembagian wilayah besar yang telah terdata oleh WHO diantaranya di Afrika berjumlah 805.000 orang perawat, di Amerika berjumlah 5.259.000 orang perawat, di Asia Tenggara berjumlah 2.224.000 orang perawat, di Mediterania Timur berjumlah 870.000 orang perawat, dan terakhir di wilayah Pasifik Barat dengan jumlah 3.600.000 orang perawat dengan total keseluruhan 19.380.000 orang perawat di Dunia. (WHO, 2012).

Badan Pengembangan dan Pemberdayaan Sumber Daya Manusia Kesehatan (BPPSDMK) menyebutkan jumlah perawat di Indonesia yang sudah terdata berdasarkan rekapitulasi jumlah tenaga keperawatan di Indonesia tahun 2016 adalah berjumlah 296.876 orang perawat, sedangkan di Sumatera Barat jumlah perawat yang sudah terdata oleh BPPSDMK pada tahun 2016 berjumlah 7.617 orang perawat (BPPSDMK, 2017).

Berdasarkan data yang didapat di ruang rawat inap Ambun Suri RSUD Dr. Achmad Mochtar Bukittinggi jumlah perawat keseluruhan bejumlah 83 orang perawat dengan pembagian ruangan
Ambun Suri lantai 1 berjumlah 25 orang perawat, Ambun Suri lantai 2 berjumlah 21 orang perawat, Ambun Suri lantai 3 berjumlah 21 orang perawat dan Ambun Suri lantai 4 berjumlah 16 orang perawat. Hasil dari wawancara yang dilakukan oleh peneliti pada mengelola emosi dan mengenal emosi orang lain, kemudian 3 perawat lagi mengatakan tidak stres ketika bekerja.

Selain itu penting juga diketahui oleh para perawat mengenai adanya hubungan kecerdasan emosional dengan stres kerja, sehingga perawat dapat berupaya meningkatkan kecerdasan emosionalnya untk mengelola stres kerja dengan baik. Melihat kondisi diatas, peneliti tertarik meneliti tentang "Hubungan kecerdasan emosional dengan tingkat stres kerja perawat di Rumah Sakit Dr. Achmad Mochtar Bukittinggi."

tanggal 28 Februari 2018 dengan 8 orang perawat, 5 perawat mengatakan kadang-kadang mengalami stres ketika bekerja, dan tindakan yang dilakukan oleh perawat yang mengatakan stres kadang-kadang dari hasil wawancara peneliti yaitu perawat melakukan .

\section{METODE PENELITIAN}

Desain penelitian yang digunakan adalah penelitian Deskriptif Analitik, yaitu mengetahui hubungan antara dua variabel yaitu independen dan dependen dari kelompok subjek yang bertujuan untuk mengetahui adanya hubungan kecerdasan emosional dengan stres kerja perawat di ruang rawat inap Ambun Suri RSUD Dr. Achmad Mochtar Bukittinggi, dengan 
pendekatan Cross Sectional Study dimana pengumpulan variabel independen dan variabel dependen dilakukan bersamaan atau sekaligus (Notoadmodjo, 2010).

Penelitian ini telah dilakukan di ruang rawat inap Ambun Suri RSUD Dr. Achmad Mochtar Bukittinggi pada bulan April - Mei 2018. Populasi dalam penelitian ini adalah perawat di seluruh ruang rawat inap Ambun Suri ada 83 orang di RSUD Dr. Achmad Mochtar Bukittinggi dimana seluruh anggota populasi dijadikan sampel. Untuk melihat hubugan keduanya digunakan uji stastistik Chi-square dengan cara komputerisasi hingga metode SPSS (Statiscal Product and Service Solution). Untuk melihat kemaknaan perhitungan statistik digunakan batasan kemaknaan 0,05 sehingga jika nilai $p<0,05$ maka secara statistik disebut "bermakna" dan jika $p>0,05$ maka hasil hitung tersebut tidak bermakna. Data ini akan diolah menggunakan program komputer yaitu SPSS.

\section{HASIL DAN PEMBAHASAN}

\section{Distribusi Frekuensi Kecerdasan Emosional Perawat}

Kecerdasan emosional perawat merupakan data kategorik, sehingga distribusi frekuensinya tersaji pada tabel berikut :

\section{Tabel 1}

Distribusi Frekuensi Kecerdasan Emosional Perawat di Ruang Rawat Inap Ambun Suri RSUD Dr. Achmad Mochtar Bukittinggi

\begin{tabular}{llll}
\hline No & $\begin{array}{l}\text { Kecerdasan } \\
\text { Emosional }\end{array}$ & $(f)$ & $(\%)$
\end{tabular}

\begin{tabular}{cccc}
\hline 1 & Rendah & 4 & 4.8 \\
2 & Sedang & 70 & 84.3 \\
3 & Tinggi & 9 & 10.8 \\
\hline & Jumlah & $\mathbf{8 3}$ & $\mathbf{1 0 0}$
\end{tabular}

Berdasarkan tabel diatas, diketahui bahwa sebahagian besar responden mempunyai tingkat kecerdasan emosional yang sedang yaitu sebanyak 70 orang $(84.3 \%)$.

\section{Distribusi Frekuensi Tingkat Stres Kerja Perawat}

Tingkat stres kerja Perawat merupakan data kategorik, sehingga distribusi frekuensinya tersaji pada tabel berikut :

Tabel. 2

Distribusi Frekuensi Tingkat Stres Kerja Perawat di Ruang Rawat Inap Ambun Suri RSUD Dr. Achmad Mochtar Bukittinggi

\begin{tabular}{llll}
\hline No & $\begin{array}{c}\text { Tingkat Stres } \\
\text { Kerja }\end{array}$ & $(f)$ & (\%) \\
\hline 1 & Normal & 57 & 68.7 \\
2 & Ringan & 26 & 31.3 \\
\hline & Jumlah & $\mathbf{8 3}$ & $\mathbf{1 0 0}$ \\
\hline
\end{tabular}

Berdasarkan tabel diatas, diketahui bahwa sebahagian besar responden mempunyai tingkat stres yang normal yaitu sebanyak 57 orang (68.7\%), pada perawat di Rumah Sakit Achmad Mochtar Bukittinggi. Hasil analisis statistik untuk mengetahui hubungan kecerdasan emosional perawat dengan tingkat 
stres kerja Perawat di Rumah Sakit Achmad Mochtar Bukittinggi, dapat dilihat pada tabel dibawah sebagai berikut :

\section{Tabel 3 \\ Hubungan Kecerdasan Emosional Perawat dengan Stres Kerja Perawat di Ruang Rawat Inap Ambun Suri RSUD Dr. Achmad Mochtar Bukittinggi}

\begin{tabular}{|c|c|c|c|}
\hline \multirow{2}{*}{$\begin{array}{l}\text { Kecerdas } \\
\text { an } \\
\text { Emosion }\end{array}$} & Tingkat & Kerja & \multirow{2}{*}{ Total } \\
\hline & Normal & Ringan & \\
\hline al & $\%$ & $\%$ & $\mathbf{N}$ \\
\hline
\end{tabular}

\begin{tabular}{lccccccc}
\hline Rendah & 0 & 0 & 4 & 100 & 4 & 100 & \\
Sedang & 48 & 68.6 & 22 & 31.4 & 70 & 100 & 0.0 \\
Tinggi & 9 & 100 & 0 & 0 & 9 & 100 & 02 \\
& & & & & & & \\
\hline Total & $\mathbf{5 7}$ & $\mathbf{6 8 . 7}$ & $\mathbf{2 6}$ & $\mathbf{3 1 . 3}$ & $\mathbf{8 3}$ & $\mathbf{1 0 0}$ &
\end{tabular}

Berdasarkan tabel diatas diketahui hasil analisis hubungan antara kecerdasan emosional dengan tingkat kerja Perawat, yaitu diperoleh ada sebanyak 48 orang (68.6\%) Perawat yang kecerdasan emosionalnya sedang tidak mengalami stres kerja atau normal.

Berdasarkan hasil uji statistik menunjukkan bahwa terdapat hubungan yang signifikan antara kecerdasan emosional perawat dengan tingkat stres kerja Perawat di Rumah Sakit Achmad Mochtar Bukittinggi, ditandai dengan nilai $P$ $=0,002<\alpha(0,05)$, yang artinya $\mathrm{H}_{0}$ ditolak.

Penelitian yang dilakukan oleh Yurista (2011), diketahui bahwa dari 100 subjek (perawat di Rumah Sakit Jiwa) diketahui bahwa kecerdasan emosi pada perawat Rumah Sakit Jiwa sebesar 36 persen pada kategori rendah, dan 64 persen pada kategori tinggi. Hasil kategorisasi ini menunjukkan bahwa umumnya perawat di Rumah Sakit Jiwa memiliki kecerdasan emosi yang tinggi.

Menurut Nurita (2012), menunjukkan bahwa terdapat korelasi positif yang signifikan antara kecerdasan emosional dengan kinerja perawat semakin tinggi tingkat kecerdasan emosional yang $P$ dimiliki subjek, maka semakin tinggi Val pula tingkat kinerja perawatnya. ue Sebaliknya jika semakin rendah tingkat kecerdasan emosional yang dimiliki subjek maka akan semakin rendah pula tingkat kinerja .0 perawatnya.

02 Diharapkan perawat mampu meningkatkan kecerdasan emosional dalam pemberian asuhan keperawatan agar perawat terhindar dari stres kerja dan mampu memberikan asuhan keperawatan sesuai dengan SOP (Standar Operasional Prosedur).

Menurut penelitian yang dilakukan oleh Martina (2012), menunjukkan bahwa 80 orang perawat yang bekerja di ruang rawat inap mengalami stres kerja dalam tingkat sedang (86\%). Penelitian yang sama dilakukan oleh Simanjorang, 2008 mengatakan bahwa perawat mengalami tingkat stres kerja yaitu sedang.

Menurut penelitian Gunawati (2006), mengatakan tingkat stres kerja yang terjadi banyak pada perempuan mengalami peningkatan 30\% dari pada laki-laki.

Diharapkan pada perawat untuk meningkatkan kecerdasan emosional dalam mengendalikan emosinya. Apabila emosinya tidak terkontrol 
maka akan berpengaruh pada asuhan keperawatan yang akan diberikan, sehingga dalam melakukan pekerjaan perawat akan mengalami stres kerja.

Penelitian ini sejalan dengan teori Mayer \& Salovey (Mubayidh, 2006) yang mendefinisikan kecerdasan emosional sebagai suatu kecerdasan sosial yang berkaitan dengan kemampuan individu dalam memantau baik emosi dirinya maupun emosi orang lain, dan juga dalam membedakan emosi dirinya dengan emosi orang lain, dimana kemampuan ini digunakan untuk mengarahkan pola pikir dan perilakunya. Berdasarkan pendapat diatas dapat di tarik kesimpulan, kecedasan emosional merupakan kemampuan individu untuk dapat memahami emosi diri sendiri dan orang lain untuk dapat menghadapi masalah, tantangan dan tekanan atau stres yang dihadapi dalam kehidupan dan pekerjaan sehari - hari.

Menurut Baron (dalam Stein, 2002), seseorang yang memiliki kecerdasan emosi yang tinggi memiliki kemampuan dalam mengatasi tuntutan dan tekanan lingkungan, berbagai masalah atau tantangan yang muncul dalam hidupnya daripada seseorang yang lebih rendah kecerdasan emosinya.

$$
\text { Pendapat lainnya yang }
$$

disampaikan oleh Rosalina (2008), mengatakan bahwa kecerdasan emosi pada perawat akan sangat menentukan perilaku melayani pasien, karena perawat yang memiliki kecerdasan emosional yang baik dapat mengontrol emosi emosinya pada saat berinteraksi langsung dengan pasien maupun keluarganya.
Hasil penelitian yang dilakukan oleh Oryza \& Suseno (2009), menyatakan bahwa terdapat hubungan negatif yang signifikan antara kecerdasan emosional dengan stres kerja.

Hasil penelitian lainnya yang dilakukan oleh Maria dkk, (2007), yang menyatakan bahwa kecerdasan emosi secara signifikan dapat menurunkan stres kerja pada perawat dan juga penelitian yang dilakukan oleh Kusumawati (2009), menunjukkan uji statistik diatas didapat, bahwa hipotesis dapat ditegakkan yaitu ada hubungan negatif dan bermakna antara tingkat kecerdasan emosional dengan tingkat stres kerja. Hal ini berarti semakin tinggi tingkat kecerdasan emosional maka semakin rendah tingkat stres kerja, dan diperkuat dari penelitian yang dilakukan oleh Zuhkri (2016), mengatakan ada hubungan negatif antara kecerdasan emosi dan tingkat stres kerja, semakin tinggi kecerdasan emosi semakin rendah tingkat stres kerja yang dialami perawat. Jadi hipotesa yang berbunyi : "Ada hubungan antara kecerdasan emosi dan tingkat stres kerja pada perawat" dapat diterima.

Sedangkan menurut asumsi peneliti hubungan kecerdasan emosional dengan tingkat stres kerja pada perawat sangat erat sekali karena semakin tinggi kecerdasan emosional yang dimiliki oleh perawat akan semakin rendah stres yg akan dialami oleh perawat atau bisa dikatakan normal, begitupun sebaliknya apabila semakin rendah kecerdasan emosional yang dimiliki oleh perawat akan semakin tinggi stres yang akan dialami oleh perawat tersebut dalam pemberian asuhan keperawatan, karena dengan 
kecerdasan emosional yang tinggi perawat akan mampu mengontrol stres ketika sedang bekerja, apabila perawat memiliki kecerdasan emosional yang tinggi stres kerja akan rendah maka pelayanan asuhan keperawatan akan bermutu dan terjalin pelayanan yang ramah antara perawat dengan pasien.

Diharapkan kepada perawat untuk dapat mengontrol emosinya dalam melakukan tindakan atau pekerjaan, karena kecerdasan emosional sangat mempengaruhi tingkat stres kerja seseorang. Diharapkan juga perawat dapat menambah wawasan dan ilmu pengetahuan mengenai kecerdasan emosional sehingga tidak berpengaruh pada stres kerjanya dan pemberian asuhan keperawatan sesuai dengan SOP (Standar Operasional Prosedur)

\section{SIMPULAN}

Hasil penelitian yang dilakukan tentang hubungan kecerdasan emosional perawat dengan tingkat stres kerja Perawat di Rumah Sakit Achmad Mochtar Bukittinggi, dengan jumlah responden 83 orang, maka dapat disimpulkan:

1. Diketahuinya bahwa sebahagian besar responden mempunyai tingkat kecerdasan emosional yang sedang yaitu sebanyak (84.3\%), untuk perawat di Rumah Sakit Achmad Mochtar Bukittinggi.

2. Diketahuinya bahwa sebahagian besar responden mempunyai tingkat stres yang normal yaitu sebanyak $(68.7 \%)$ pada perawat di Rumah Sakit Achmad Mochtar Bukittinggi.
3. Terdapat hubungan yang signifikan antara kecerdasan emosional perawat dengan tingkat stres kerja Perawat di Rumah Sakit Achmad Mochtar Bukittinggi, ditandai dengan nilai $p=0,002<\alpha(0,05)$, yang artinya $\mathrm{H}_{0}$ ditolak.

\section{SARAN}

Diharapkan pada peneliti selanjutnya dapat menjadikan hasil penelitian ini sebagai pedoman dalam melaksanakan penelitian lebih lanjut, dianjurkan dengan judul pengaruh terapi ayat suci Al- Quran terhadap penurunan tingkat stres perawat dengan rentang waktu yang lebih lama dan sampel yang lebih besar, sehingga hasil penelitiannya bisa lebih valid.

\section{DAFTAR PUSTAKA}

1. Agency, B. \& Tridhonanto, A. (2009). Melejitkan Kecerdasan Emosi Buah Hati. Jakarta: Elex Media Komputindo.

2. Agus Efendi. (2005) Revolusi Kecerdasan Abad 21. Bandung. Alfabeta.

3. Armiyanti, E.O. (2008). Pengaruh kecerdasan emosional terhadap kecenderungan perilaku delinkuen pada remaja. Psikovidya, Volume: $12 . \quad 1-10$ at http://klinis.wordpress.com (diakses 15 November 2011).

4. Darmawan. (2008). Pengaruh Motivasi Kerja dan Kemampuan Kerja Terhadap Kinerja Karyawan. Universitas Brawijaya.

5. Goleman, Daniel. (2009). Emotional Intelligence 
(terjemahan). Jakata : PT Gramedia Pustaka Utama.

6. Haryono, D. S. (2009). Hubungan antara beban kerja, stress kerja dan tingkat konflik dengan kelelahan kerja perawat di rumah sakit Islam Yogyakarta.

7. Hermita. (2011). Pengaruh Stres Kerja Terhadap Kinerja Karyawan pada PT. Semen Tonasa (PERSERO) Pongkp. e Skripsi Fakultas Ekonomi Universitas Hasanudin Makasar.

8. Martin, Anthony. (2003) Emotional Quality Management, Refleksi,Revisi, dan Revitalisasi Hidup Melalui Kekuatan Emosi. Jakarta : Arga

9. Kyle \& Carman. (2015). Buku Ajar Keperawatan Pediatri Edisi 2. Jakarta : EGC.

10. Mubayidh, Makmun. (2006) .Kecerdasan dan Kesehatan Emosional Anak: Referensi Penting Bagi Para Pendidik dan Orang tua. Jakarta: Pustaka AlKautsar

11. Mulyadi, S. (2005). Kecerdasan emosional anak penting dikembangkan. Jakarta. Tersedia dalam http://www.pelita.or.id/baca.php? $\underline{i d=16965}$
12. Mulyani, S. (2008), "Analisis Pengaruh Faktor-Faktor Kecerdasan Emosi terhadap Komunikasi Interpersonal Perawat dengan Pasien di Unit Rawat Inap RSJD Dr. Amino Gondohutomo Semarang”, Tesis: Universitas Diponegoro Semarang.

13. Notoadmojo. (2010). Metodologi Penelitian Kesehatan. Jakarta : PT. Rineka Cipta.

14. Oginska - Bulik, N. (2005). Emotional intelligence in the workplace: exploring its effects on occupational stress and health outcomes in human service workers. International Journal of Occupational Medicine and Environmental Health, 18 (2), 167 $-17$.

15. Purwanto. (2007).Kepuasan Pasien terhadap Pelayanan Rumah Sakit. Available online.

16. Tridhonanto, A. (2009). Melejitkan Kecerdasan Emosi Buah Hati. Jakarta:Elex Media Komputindo.

Wong, D. (2009). Buku Ajar Keperawatan Pediatrik. Volume 1. Jakarta : Buku Kedokteran EGC. 